We found several snares and obtained some images of poachers with the camera-traps. The forest surroundings have been cleared for subsistence agriculture by communities living in villages to the north and west of the forest. Despite the forest being fully inside a Nature Reserve, and the communities being aware of its borders and regulations, there is no active protection, mirroring the condition of other forests in the southern and western part of the Udzungwa Mountains. We recommend that appropriate measures are enacted to ensure the protection of this important forest.

Rasmus Havmøller and Flemming Pagh Jensen Natural History Museum of Denmark, Copenhagen University-Centre for Macroecology, Evolution \& Climate, and Centre for GeoGenetics Oestre Voldgade, Copenhagen, Denmark

E-mail rghavmoller@snm.ku.dk

MARCo Ciolli Dipartimento di Ingegneria Civile Ambientale e Meccanica, University of Trento, Trento, Trentino, Italy

Francesco Rovero Museo delle Scienze-Corso del Lavoro e della Scienza, Trento, Trentino, Italy

\section{Student Conference on Conservation Science in Cambridge, UK}

The latest in a 15-year series of annual Student Conferences on Conservation Science was held in the Department of Zoology, University of Cambridge on 25-27 March 2014. The conferences are aimed at early-stage researchers in conservation science and this one was attended by over 300 people, including 193 postgraduate students from 60 countries. At the heart of the conference were 31 talks and 109 posters on a vast range of topics, contributed by research students. The conference aims to accept presentations on as many aspects of conservation science as possible, including the social sciences. Every student contributing a talk or poster was given written feedback on their presentation by a senior conservationist.

Intermingled with the student contributions were inspiring plenary lectures given by Professor Chris Johnson (Lessons for conservation from historical and prehistorical changes), Professor Amanda Vincent (Seahorse conservation practice and science), Dr Camilla Toulmin (Incentives for sustainable wildlife use) and Julia Marton-Lefevre (The science-policy interface from an IUCN perspective). There were two workshop sessions, offering eight 90-minute workshops. Experts on writing and publishing papers, fund-raising, designing research projects, statistics, genetics, economics and making conservation work in practice presented workshops with a how-to focus.

A special feature of the conference was the role played by conservation practitioners. Overall, the conference was visited by 79 staff or representatives from 33 conservation agencies, institutes and NGOs, who chaired sessions, ran workshops and engaged student delegates in discussions during breaks. The poster session Who's Who in Conservation? allowed 25 conservation agencies, institutes and NGOs to present their work and answer queries.

The conference had a real buzz as enthusiastic and able scientists worked hard, learned a lot, taught each other a lot and had a good time. The next conference in the Cambridge series will be 25-27 March 2015 (see www.sccs-cam.org). Sister conferences with similar objectives have been held in Bangalore (India; www.sccs-bng.org), New York (USA; symposia.cbc.amnh.org/sccsny), Beijing (China; www.sccscam.org) and Brisbane (Australia; sccs-aus.org). Further conferences in these series are also planned.

RHYS GREEN Department of Zoology, University of Cambridge, UK.E-mail reg29@hermes.cam.ac.uk

\section{1st annual Whitley Awards}

The 21st annual Whitley Awards Ceremony was held on 8 May 2014 at the Royal Geographical Society in London. The flagship event of UK-based charity the Whitley Fund for Nature was hosted by wildlife presenter Kate Humble, and saw eight conservation leaders from seven countries receive GBP 35,000 each in project funding over 1 year in support of their work. The Awards were presented by the charity's patron, HRH The Princess Royal.

A special Whitley Gold Award was presented to 2008 Whitley Award winner Jean Wiener of Haiti for his outstanding contribution to the conservation of coastal ecosystems with the help of Continuation Funding from WFN.

The 2014 Whitley Award Winners are Shivani Bhalla, Kenya; Marites Gatan-Balbas, Philippines; Monica Gonzalez, Ecuador; Melvin Gumal, Malaysia; Paula Kahumbu, Kenya; Fitryanti Pakiding, Indonesia; Stoycho Stoychev, Bulgaria; and Luis Torres, Cuba.

For more information on the Whitley Fund for Nature, the Whitley Awards and the winning projects, see http://www.whitleyaward.org/. See p. 467 for the call for applications for the 2015 Whitley Awards.

DAVID WALLIS Whitley Fund for Nature, London, UK E-mail david@whitleyaward.org 